\title{
Factors Affecting the Implementation of Good Agricultural Practices (GAP) among Coffee Farmers in Chumphon Province, Thailand
}

\author{
Pongthong Pongvinyoo*, Masahiro Yamao, Kenji Hosono \\ Graduate School of Biosphere Science, Hiroshima University, Japan \\ *Corresponding author: drkokung01@hotmail.com
}

Received June 12, 2014; Revised July 01, 2014; Accepted July 03, 2014

\begin{abstract}
Thai coffee farmers have exerted much effort to develop GAP-based Robusta coffee production since 2008. However, they still lacked knowledge and experience. Their conventional farming activities are often in conflict with GAP system, which might be caused by the limitation of GAP extension procedure. The objectives of this study were to investigate the current perceptions of GAP Coffee Farmers (GCF)'s understanding of GAP, and to identify the factors affecting such perceptions. A series of surveys were conducted in Chumphon province by using structured questionnaires which were administered to fifty-six (56) coffee farmers who applied for GAP certificates in 2013. This study found that farmers' GAP self-confidence positively affected, while farmers' GAP experiences had negative impact to the farmers' understanding of GAP. This showed the lacking of continuity of GAP extension service, although the GAP promotion was an important factor to increase the farmers' GAP understanding. The very small number of agricultural extension officers was cited as a detrimental factor. The GAP manual should also be simplified to suit the GCFs educational background.
\end{abstract}

Keywords: Good Agricultural Practices (GAP), Robusta coffee, Chumphon, Thailand

Cite This Article: Pongthong Pongvinyoo, Masahiro Yamao, and Kenji Hosono, "Factors Affecting the Implementation of Good Agricultural Practices (GAP) among Coffee Farmers in Chumphon Province, Thailand." American Journal of Rural Development, vol. 2, no. 2 (2014): 34-39. doi: 10.12691/ajrd-2-2-3.

\section{Introduction}

GAP (Good Agricultural Practices)is a voluntary codified system that is related to practical, efficient onfarm and off-farm processes aimed towards sustainability and equity for small-scale farmers. [11,15] GAP was introduced by FAO and implemented in many agricultural producing countries [16]. GlobalGAP is one of the wellknown GAP standards in the world for pursuing high quality food safety for the agricultural food producer countries. [1] GlobalGAP standards are widely accepted by international markets such as EU and USA markets. [9] However, the strictness and difficulties of the GlobalGAP standard could not be satisfied for Thai farmers' GlobalGAP practical implementation. Thailand is one of the agricultural countries which adopted the GAP concept to increase the competitiveness, food security, and standardization of Thai agricultural products. With standard and framework developed, Thai National GAP could satisfy the demand of international markets for high quality safe food.

Coffee is one of the sensitive agricultural products for the export market. [12] Therefore, GAP was chosen as an important public standard to increase coffee farmers' competitiveness and guarantee food safety for domestic consumption and the export markets. It needed a globally acceptable standard as the minimum requirement for exporting and guarantees the food safety for exported agricultural commodities. [1] However, Thai coffee farmers still encountered problems such as lack of technical knowledge and experience on GAP practical implementation.

The inefficiency of GAP implementation showed the low level of farmers' understanding of GAP. [5] Thai farmers' adherence to conventional farming methods was the challenge for GAP extension institutions in promoting the standard procedure for the farmers, which could improve the farmers' perception of the GAP standards. However, the practical GAP inspection procedures and limitations of extension services were also causes of farmers' low GAP understanding of GAP and led to poor practical implementation in the past [1]. Therefore, the current problems might be caused by the inefficiency of extension services provided by the Ministry of Agriculture and Cooperative (MOAC) authorities [2].

In Thailand, the coffee market condition did not directly encouraged the farmers to participate in the GAP theme. Not only was there a public standard for coffee commodities, there appeared to be a private standard provided by the beggest local private coffee processing company. This private standard provided higher coffee price than general coffee for their members, but the farmers were required GAP certification as their membership qualification. In addition, GAP coffee 
products could be sold at the same price as the ordinary coffee. This means only nominal GAP certification was demanded from the local coffee farmers. These conditions might reduce the farmers' understanding of the GAP standard in the long term [6] which could influence the production of unstandardized products under the GAP theme.

The limitations of GAP extension services and ineffective market conditions did not encourage the farmers to participate in the GAP theme. Therefore, the farmers did not completely adopt GAP standards into practical implementation, which might result to inferior Thai quality standards. [1,2] Furthermore, very few studies focused on the Thai national GAP in coffee communities. The link between the coffee farmers' GAP perception and GAP implementation is unknown. The purpose of this study was to find out the factors affecting the GAP perception among GAP coffee farmers (GCFs), and identifying the implementation constraints of GAP extension services and its market conditions. This study also recommended some appropriate ways for the development of GAP extension methods.

\section{Thai National GAP Scenario}

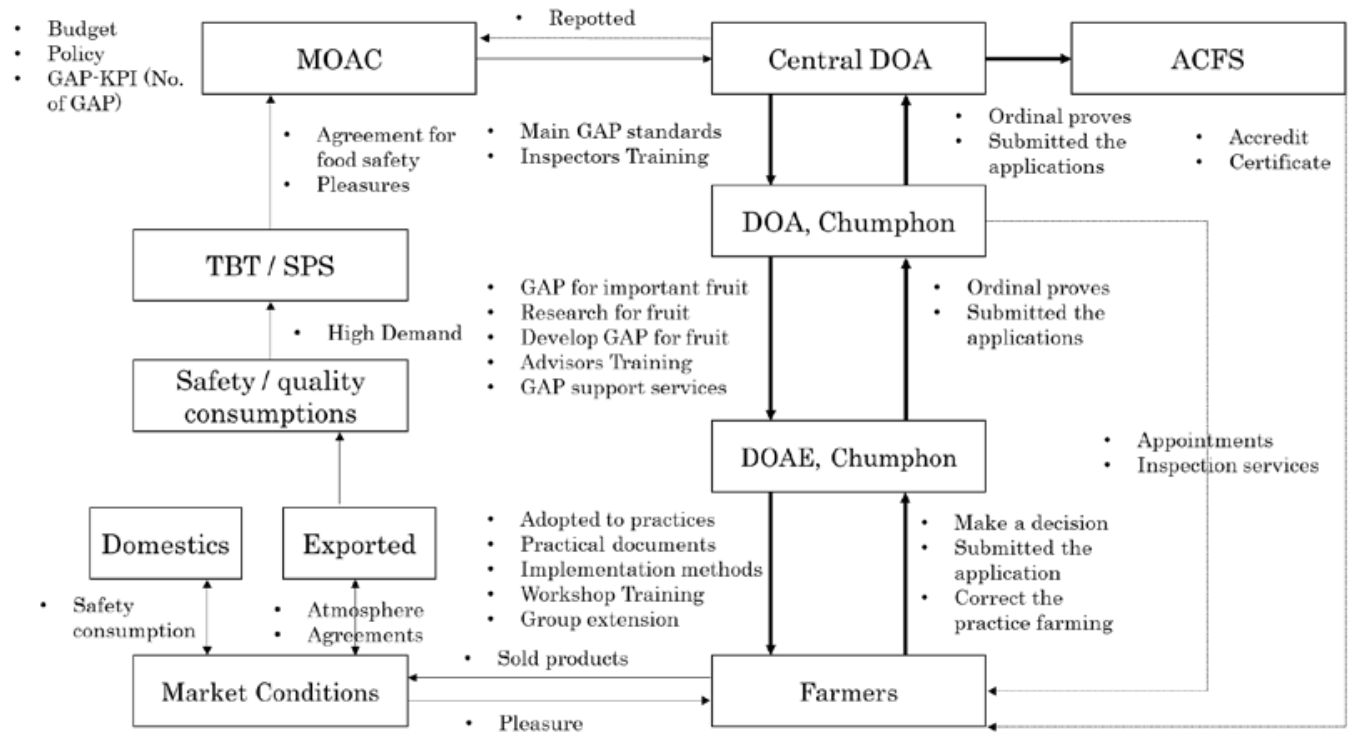

Figure 1. Thai National GAP institutions' functions and their practical implantation

Farmers who like to acquire GAP certification have to submit the application to the local DOA or DOAE. [1] The farmers were trained and instructed about GAP standard by the extension officers through the many kinds of extension activities (Figure 1) without any registration fee. Later, the local DOAE official inspect the farmers' orchards and submit the approved farmers list to the local DOA. Then, DOA officers who were qualified as GAP inspectors would directly make an appointment with each farmers for inspection. Afterwards, the farmers were checked for their GAP implementation on their farm site based on the 84 control points, and 22 critical control points of the GAP standards. Those control points consisted of 8 GAP elements which are water resource (10.7\%), cultivation site $(10.7 \%)$, use of agricultural substance $(11.9 \%)$, product storage and on-site transportation (14.3\%), disease and pest-free production
GAP-established practical manuals have been promoted by governments especially in ASEAN countries including Thailand. [2] The Ministry of Agriculture and Cooperatives (MOAC) first instituted GAP under its Agricultural Commodity Standard on Good Agricultural Practice for Food Crops in 2003. [16] Since then, the Agricultural Standards Committee has revised some standards for better acceptance in terms of both quality and safety of Thai agricultural products. [14] This is to keep up with rapidly changing global standards and to improve product competitiveness in the world market. [2] Thai food safety regulation is based on Quality Management System (QMS). Within the QMS, three important bodies under the supervision of the MOAC have been established with specific advisory, certification and accreditation roles. [14] The Department of Agriculture (DOA) is mainly charged with an advisory function in encouraging and training farmers for the adoption of GAP. The Department of Agriculture Extension (DOAE) is tasked with the initial certification process after compliance. The National Bureau of Agricultural Commodities and Food Standards (ACFS) has the responsibility to assist GAP-certified farmers and their products to ensure products rigidly maintain GAP standards and are certified safe for domestic consumption and accredited for export. 
components could influence human perception, including individual personalities, motivation, emotion, proficiency, and situation. Furthermore, self-confidence and mastery experiences played roles in increasing human perception [2,8]. Farmers' self-confidence refers to the belief in themselves through their abilities to achieve personal goal. [4] However, economic compensation and promotion motivated the farmers to practice conservation [13]. GAP extension services and market conditions possibly motivated the farmers to acquire GAP knowledge for their future implementation. Therefore, perception was the motivation evaluator. Many previous studies on Thai national GAP revealed that the farmers' individual personality affected their perception $[1,6,10]$. Farmers field school (FFS) was also an influential factor that affected the farmers in implementing GAP knowledge on their pomelo orchards in Chaiyaphum province [1]. Thus, farmers' different personality backgrounds might not have influenced GAP implementation rather than their opportunity or access to practices. Amekawa [1] indicated that the GAP market and inspection services were among the problems of Thai national GAP inefficiency. However, those studies did not deeply analyze the link between the farmers' GAP perception and its components. Consequently three important components (socioeconomics profile, experiences and self-confidence) were chosen and identified as the target components of this study's measure of perception, to evaluate the efficiency and constraints of the GAP for Robusta coffee extension services and its market conditions for the GAP implementation by GCF. There were no studies on the link between the farmers' self-confidence and GAP implementation from the farmers' side.

\section{Methodology}

The pre-survey was conducted on 10 coffee farmers in Chumphon province (Sawee, Tasae and Pato districts) which are among the biggest coffee cultivation areas in Thailand. There was not much difference as regards to coffee cultivation, socio-economics perceptions and opinions on GAP standards among the farmers interviewed. Due to the homogeneous distribution of the respondents, structured questionnaires were administered on 56 farmers, accounting for $13.6 \%$ of 411 GAPpracticing farmers in seven villages in the province. These farmers had expressed their willingness to renew their GAP certificates in 2013. This means the chosen respondents still remembered and were familiar with the GAP instructions which were extended by the government officers. Extension officers were also interviewed about the local extension methods used during the same period.

The structured questionnaires attempted to investigate the socio-economic characteristics of the farmers, categorize their current practical farming, perceptions, constraints, and opinions towards GAP regulations for Robusta coffee, including their market access and extension services. The questionnaires used the 3 Likert scales ( 2 = agree, $1=$ Not sure, and $0=$ disagree) as the measure for the GCFs' GAP perception of their GAP understanding of each element while 5 Likert scales (5 = strongly confident, $4=$ confident, $3=$ not sure, $2=$ not confident, and 1 = strongly not confident) for their GAP self-confidence evaluation. GCFs have complied with the GAP minimum requirements for the certification. Therefore, the farmers' GAP perception in this study was calculated by the summation of mean score of perception among GCFs on their GAP understanding of 84 control points (minimum 51\% were required for certification) [1] from the GAP manuals which were distributed to GCFs in the study area by DOA and DOAE.

The data were arranged and described by statistical tools, and were analyzed to identify the factors affecting the GAP perception among GCFs of their GAP understanding by using simple linear regression analysis for 34 farmers (60.7\%) inwhich their perception of QGAP understanding missing value must be lower than $10 \%$. In consequence, the socio-economic profiles in this study included farmers' age, years of education, cultivation area, and income per rai as the independent variables, as well as experiences denoting their years of practical coffee and GAP cultivation. In addition, farmers' self-confidence was measured by farmers' self-evaluation toward their own GAP practical farming experiences in each element. The extension services and market condition were also analyzed by using qualitative methods.

\section{Results of the Study}

The results of this study were divided into 3 sections as follow:

\subsection{Socio-economic Profile of Respondents}

The respondents of this study were almost equally divided by gender with $48 \%$ female and $52 \%$ male. Their ages ranged from 31 to $60 ; 30.4 \%$ of the respondents are in the 31-40 age group, followed by those in the 51-60 age group. Three-fourths of the respondents worked on their farms by employing family labor because coffee cultivation and post-harvest do not heavily demand labor and skills. Only during the short harvest time were extra workers employed with wages fixed at THB $1.0-3.5 / \mathrm{kg}$ of harvested coffee. Forty-four point six percent (44.6\%) of the respondents owned lands of up to 20 rai ( 1 rai $=0.16$ ha) per family, while only $21.0 \%$ had land smaller than 10 rai. The farmers' coffee experiences ranged from 4 to 37 years: $41.1 \%$ of the respondents were in 11-20 years experiences group, followed by those in the 21-30 years experiences (26.8\%). However, the difference of the farmers' coffee experiences has not made any variance on their income. The majority of farmers (46.4\%) got incomes of between 10,000 - 15,000 THB/rai, 19.6\% had 11-20 years coffee experiences and $16.0 \%$ had $21-30$ years' experience. A majority of 17 farmers (30.3\%) graduated from primary school or have lower educational level, and 8 farmers (14.3\%) reached higher levels.

\subsection{GAP Perception among GCFs and Factors Affecting Such Perception}

The farmers primarily received GAP information from the MOAC; therefore they made the decision to conduct GAP practical farming and qualify for the certificate according to the market situation. In general the GAP certificate was usually used as a marketing tool from the buyer side. The mean scores of perception of the GCFs' 
GAP understanding on the control points in each elements perception are shown in Table 1.

Table 1. Mean score of GAP perception of the farmers' understanding

\begin{tabular}{llll}
\hline No & GAP elements & Mean & S.D. \\
\hline 1 & Water source & 0.85 & 0.23 \\
2 & Cultivation site & 0.77 & 0.33 \\
3 & Use of agricultural hazardous substance & 0.85 & 0.22 \\
4 & Product storage and on-site transportation & 0.97 & 0.11 \\
5 & Disease and pest-free production & 0.94 & 0.16 \\
6 & Management of quality production & 0.98 & 0.08 \\
7 & Harvesting and post-harvesting handling & 0.80 & 0.27 \\
8 & Data recording & 0.75 & 0.30 \\
\hline
\end{tabular}

GAP perception among GCFs $(Y)$ : mean $=6.90$, S.D. $=0.987$

The farmers had the lowest GAP understanding (0.75) on the "data recording" element even if the local GAP extension officers provided the data recording forms to every GCFs in the area. However, GCFs familiar and comfortable with their conventional farming methods did not bother to record their GAP farming procedures.
Furthermore, the documents had unsuitable format for them. On the other hand, the farmers had the highest GAP understanding (0.98) on the "management of quality agricultural production" element which was strictly checked by the GAP inspectors. Simple linear regression analysis was performed to examine the factors affecting perception of GCFs' GAP understanding among 34 GCFs of each independent variable (socio-economic profiles, coffee experiences and self-confidence). The results are shown in Table 2. The results illustrated that farmers' years of school $\left(\mathrm{X}_{2}\right)$, farmers' cultivation area $\left(\mathrm{X}_{3}\right)$, and farmers' self-confidence $\left(\mathrm{X}_{7}\right)$ had positive and significant impact on the perception of GCFs' GAP understanding (Y). However, farmers' GAP cultivation experiences $\left(\mathrm{X}_{6}\right)$ had negative and significant impact on $\mathrm{Y}\left(\mathrm{X}_{2}: \beta=0.452\right.$, $t$ $=2.459 ; \mathrm{X}_{3}: \beta=0.326, t=2.307, \mathrm{X}_{7}: \beta=0.450, t=2.560$, and $\mathrm{X}_{6}: \beta=-0.317, t=-2.063$ respectively, $\left.\mathrm{p}<0.05\right)$. Thus, the coefficient of determination revealed $41.3 \%$ variation in GAP perception of GAP understanding among GCFs as explained by farmers' years of education, cultivation area, GAP cultivation experience and selfconfidence.

Table 2. Summary results, regression coefficients and descriptive statistics $(n=30)$ n of selected predictors

\begin{tabular}{|c|c|c|c|c|}
\hline \multirow{2}{*}{ Predictors (unit) } & \multirow{2}{*}{ Mean } & \multirow{2}{*}{ S.D. } & \multirow{2}{*}{ t-value } & GCFs' GAP understanding (Y) \\
\hline & & & & $B$ \\
\hline $\mathrm{X}_{1}$ Age (years) & 43.52 & 12.34 & 1.25 & 0.21 \\
\hline $\mathrm{X}_{2}$ Years of education(years) & 8.11 & 3.78 & 2.46 & $0.45^{*}$ \\
\hline $\mathrm{X}_{3}$ Cultivation area (rai) & 23.64 & 13.52 & 2.30 & $0.33^{*}$ \\
\hline $\mathrm{X}_{4}$ Income per rai(Thousand THB) & 12.07 & 5.53 & -0.57 & -0.08 \\
\hline $\mathrm{X}_{5}$ Coffee cultivation experiences (years) & 18.73 & 7.41 & 0.20 & 0.03 \\
\hline $\mathrm{X}_{6}$ GAP cultivation experiences (years) & 1.47 & 0.50 & -2.06 & $-0.32 *$ \\
\hline $\mathrm{X}_{7}$ GAP self-confidences (NA.) & 3.50 & 1.11 & 2.56 & $0.45^{*}$ \\
\hline
\end{tabular}

$\mathrm{F}$ change $=4.32 * *, \mathrm{R}^{2}=0.54$, Adjust $\mathrm{R}^{2}=0.41$

${ }^{*} \mathrm{p}<0.05,{ }^{* *} \mathrm{p}<0.01$

\subsection{Constraints of GAP Implementation among GCFs}

5.3.1. Coffee farmer's GAP farming practices: GAP certification has become less attractive for farmers. This is because of the market conditions that were not directlysupporting the farmers to encourage GAP-based production. It was found that $96.4 \%$ of the respondents did not have any system for data recording. However, most of the farmers (90.0\%) were more concerned with implementation of quality agricultural production methods because the Department of Agriculture Extension (DOAE) inspectors paid much attention on these aspects as basis for checking GAP compliance. The farmers still expressed confusion about the practical GAP processes and often made mistakes. For example, $89.3 \%$ of the respondents did not separate the storage for harvested products far enough from the chemical storage. All respondents did not use concrete surfaces in the solar drying of coffee fruits contrary to the standards stated in the GAP manual. Only $35.7 \%$ of the respondents said they achieved their initial financial goals by following GAP guidelines and by applying GAP content to the other private standards.

5.3.2 Practical extension services for GAP: Extension officers were overworked and had many responsibilities with limited budget and time limitations. At present, only 12 extension officers of the DOAE are responsible for servicing more than 5,000 farmers in Chumphon and Surat Thani provinces. They provided technical information not only on coffee and other crops, but also agricultural standards such as organic farming. The extension services provided information on technical farming and implemented the standard with documents, soil check sampling, standard practical consulting and certificate for standard farming, including inspection services. The inspectors randomly checked GCFs who followed the GAP checklists only once a year. GCFs only qualified for 84 total control points, with $51.0 \%$ of compliance required for certification [1]. GAP documents distributed to GCFs with low educational background contained too many difficulties and complexities for their understanding.

5.3.3 Market conditions of GAP coffee: The local coffee market price had not influenced the farmers to make a decision to cultivate coffee following the GAP standards. GAP coffee was usually sold at the same price as the coffee conventionally produced without GAP certification. The farmers made their decision to sell their coffee under the most convenient situation for them even with a slight price difference between 3-5\%. However, buyers mixed both coffee types together without paying attention on production procedures. Therefore, the economic incentive 
from GAP coffee production was diminished [9]. The coffee price did not encourage the farmers to adopt GAP procedures.

The Thai government has set up a policy for protecting local farmers from disadvantageous and unfair competition in the world coffee market. The situation forced the processing company to responsibly purchase local coffee at first. Then they could import coffee with lower price according to the volume of domestic coffee purchased. However, the private company did not directly use the GAP certification as marketing tools. Thus, the company provided their own private standards which were not so much different from the GAP standards, and persuaded GCFs with GAP certification to sell their coffee to the company. According to the surveys, 51 (91.1\%) farmers firstly sold their products to processing companies because of easier sustainable standards which brought up to $20.0 \%$ more income to the farmers. However, the coffee bean checking processes were so strict; consequently the farmers could only get an average additional income of $5 \%$ more than the general market channel.

\section{Discussions}

The results of this study were generally consistent with those of Amekawa [1,2] that educational background of the farmers affected their choice of appropriate pesticide use methods. Farmers' year of school positively affected GCFs' GAP perception. Three-fourths of the respondents graduated from primary school or have lower level of educational background. They could not follow the content of the GAP manuals which did not explain procedures and methods simply; nonetheless they still qualified for GAP certification. GCFs' GAP perception increased in relation to their available cultivation area $\left(\mathrm{X}_{3}\right)$; however it would be decreased when the farmers got higher GAP experiences $\left(\mathrm{X}_{6}\right)$. GCFs were professional coffee farmers with average 18.73 years' experiences. Their farming methods did not make much difference on their income from coffee. GCFs possibly practiced and learned GAP by themselves after getting GAP information from the extension offices which affected the level of their GAP perception positively.

The market condition has not encouraged the farmers to continuously produce GAP-based coffee. Only certification was needed for them. The farmers were more familiar with their conventional farming methods (18.7 years) than GAP approaches (1.4 years). They adopted GAP approach only for getting the certificates by complying only with the contents strictly inspected by the inspectors. Previously they adopted their conventional methods for their practical farming which often conflicted with GAP approach (such as chemical use method).

The results of farmers' GAP experiences negatively affected the GCFs' GAP understanding indicating the inefficiency and strictness of inspection services that contributed to the situation. Although the GAP extension and promotion procedures were important factors for the development of farmers' GAP understanding, the lack of GAP extension discouraged practical implementation. Therefore, GCFs' perception of GAP understanding declined whenever they acquired more experiences on GAP. This means there were an option for the farmers to adapt their conventional farming methods with the GAP approaches, which have been discouraged by the limitation of inspection services. However, farmers' selfconfidence positively affected their GAP understanding which was supported by the social learning theory of Bandura [3]. Both theory and practicality of GAP knowledge was promoted by DOAE officers enhancing farmers' self-confidence. If farmers had better understanding of GAP content due to the efficiency of GAP advertising methods, they may increase their efforts for implementing GAP. GCFs had an advantage in increasing GAP understanding through their practices in their respective area. GCFs become disinterested with GAP after they were certified because GAP certification cannot be directly used as marketing tools from the buyer side.

Subsequently, GAP can be effectively implemented on the GCFs by conducting specific workshop or group training program. Continuous training programs should be provided to certified-GCFs to remind them about GAP. It will also maintain their GAP self-confidence which supports their intention to implement GAP. Extension officers only strongly encouraged and provided many services supporting farmers at the GAP start period. The certified local coffee farmers got 2 years certificates. However, the poor status of GAP inspection was the main constraint due to its limitation on budget and human resources, which resulted in the lack of continuous inspection services. The GAP manual should also be simplified to cater to the GCFs low educational background. It was clear that local coffee market conditions did not support the farmers to conduct GAP production. Similarly, farmers were only looking for tangible benefits from the standards which GAP could not provide for them. MOAC might have the responsibility to provide specific markets for coffee produced following the public standard. Otherwise, more intensive cooperation between government and private sector, which has an advantage on the market purchasing, is needed to further develop public standards scheme in Thailand.

\section{Conclusions}

The difficulty of GAP production methods and marketing system influenced the change of farmers' perception of their GAP understanding in the study area. It showed that GAP extension in Thailand still has many issues to address to improve GCFs' GAP implementation. MOAC has to rethink developing a continuous policy (training program, and simplify GAP manual) to support the farmers dependent on standard procedures. Regional market conditions also did not directly support the farmers engaged in GAP production. However, the private sector which has the advantages in the topical market systems should be persuaded to participate much more in the GAP scheme. The collaboration between government and private sectors, such as adoption of GAP as a part of the private sector standard, might reduce the difficulty and confusion of GCFs to adapt to too many standards. The success of collaboration might encourage the farmers to be aware of the standard which encourages comprehensive implementation. 


\section{References}

[1] Amekawa. Y., "Rethinking sustainable agriculture in Thailand: a governance perspective" Journal of Sustainable Agriculture, 34(4), 389-416. 2010.

[2] Amekawa, Y., "Can a public GAP approach ensure safety and fairness? A comparative study of Q-GAP in Thailand”, Journal of Peasant Studies, 40, 189-217. 2013.

[3] Bandura. A., "Self-efficacy mechanism in human agency", American Psychologist, 7(2), 122-147. 1982.

[4] Benabou R. and Tirole J., "Self-confidence and personal motivation”, Journal of Economics 117(3), 871-915. 2002.

[5] Buckley R. and Caple J., The theory \& practice of training (5th ed.), London, Kogan, 2007, 139-141.

[6] David C. L., Pimjai S., Nick I. T., "Fish culture in rainfed rice fields of northeast Thailand", Journal of Aquaculture 140(4), 295321. 1996.

[7] Department of Agricultural Extension, Agricultural Statistics of Thailand. Bangkok, 2011

[8] Gist. M. E., "Self-efficacy: Implications for organizational behavior and human resource management", Academy of Management Review. 12(3), 472-485. 1987.

[9] Hobb, J. E., Incentive for the adoption of Good Agricultural Practices, Background paper for the FAO expert Consultation on a Good Agricultural Practices approach. Rome, Italy, 10-12 November, 2003.
[10] Kersting, S., Wollni, M., "New institutional arrangements and standard adoption: Evidence from small-scale fruit and vegetable farmers in Thailand”. Food Policy 37, 352-362. 2012.

[11] Mausch, K., Milthofer, D., Asfaw, S., \& Waibel, H., "Impact of EurepGAP Standard in Kenya: Comparing Smallholders to Largescale Vegetable Producers", International Agricultural Research for Development. 2006

[12] Ministry of Agriculture and Cooperatives, Coffee Strategy 20092013 (in Thai), Bangkok, 2009

[13] Ryan R.L., Erickson D. L. and Young R. D., "Farmers motivations for adopting conservation practices along riparian zones in midwestern agricultural watershed",Journal of Environmental Planning and Management, 46(1), 19-37. 2003.

[14] Salakpetch, S., "Quality Management System: Good Agricultural Practices (GAP) for on-farm production in Thailand". Food and Fertilizer Technology Center. 2007

[15] Van Der Meer, C. L.,"Exclusion of small-scale farmers from coordinated supply chain: Market failure, policy failure or just economies of scale?” In: R. Ruben, M. Slingerland, and H. Nijhoff, eds. Agro-food chains and networks for development, Netherlands: Springer, 2006, 209-217.

[16] Wannamolee, W., Development of Good Agricultural Practices (GAP) for fruit and vegetables in Thailand, paper present for Training of Trainers in Good Agricultural Practices (GAP) and Benchmarking: Global GAP for Fruit and Vegetable, Sheraton Subang Hotel and Tower, Kuala Lumpur, Malaysia, 14-23 July 2008. 